\title{
Final Reflections
}

\author{
Gianfranco Verzaro
}

One of the most significant achievements of the Capacity Building project, which was finalised by the National Agency for Micro-credit, was to have identified new characteristics and issues of a sector, such as microfinance, which until the recent past was often associated with the simple offer of modest credit paid by not-for-profit institutions in favour of people or social groups who are particularly vulnerable.

From the analysis conducted in the course of the project - as well as from direct interactions with regional authorities, stakeholders, banking and financial intermediaries and numerous players within society - it became clear, in fact, that the target market for microcredit and microfinance presents somewhat different connotations today, due to the profound changes in recent years in relation to both the target beneficiary clientele and the range of microfinancial instruments that have been or will be activated. And this, as a direct result of the changes which have taken place in our society (consider, e.g., the massive immigration of individuals from developing countries) as well as the financial crisis which, in recent years, has given rise to new poverty and phenomena of financial exclusion even in areas which previously seemed to be immune.

On the supply side, we are today witnessing a differentiation in financing methods, from the moment that not-for-profit organisations were flanked by for-profit institutions, such as banks and financial intermediaries and, most recently, by new microcredit providers established in Italy under new specific legislation (the new art. 111, paragraph 1, of the Consolidated Banking Act), on whose operating norms the Banca d'Italia has opened a public consultation right in the days in which this volume goes to print. 
Simultaneously, the expansion of the range of financial instruments offered to the traditional microcredit clientele has been confirmed; this has enabled a clear differentiation between the concepts of microcredit and of microfinance and has conferred greater definitive autonomy to microcredit. Today, microcredit is, admittedly, the first among a range of microfinance instruments - including microleasing, microinsurance, housing microfinance. But still newer instruments are emerging as concrete alternative or complementary possibilities to microcredit. And this is to the credit of the Capacity Building project, which first investigated them at the technical-scientific level and then, on the basis of in-depth comparisons with market players, proposed them to regional authorities who are responsible for operational programmes co-financed by structural funds, such as tools to support microenterprise and population groups who are the most disadvantaged.

Moreover, the evolution in the structure of the offer has enabled us to reach a larger audience of final recipients, due not only to the so-called poorest of the poor (a term borrowed from the experiences of developing countries and which, in Europe, should rather be referred to social-welfare policies) but to the broader category of people who are excluded from the financial system, primarily microentrepreneurs, who are no longer "trusted" by the banks because of their precarious economic-financial status, and aspiring entrepreneurs (young, unemployed, immigrants) who, while in possession of valid microenterprise or self-employment ideas, do not have access to bank credit due to a shortage or absolute lack of collateral.

In this context, the specific task of the Capacity Building project namely, the reinforcement of public authority institutional capacities in the Italian regions of the former Convergence Objective with regard to structural funds resource programming intended for microcredit programmes - has enabled us to develop new ideas and valid methodologies even for the extension of the project to other Italian and European regions.

With the conclusion of the project, the present volume aims to provide deeper insight into the institutional capacity of the European managing authorities in relation to the planning, monitoring and evaluation of microcredit and microfinance programmes. A highly diversified framework has emerged which reveals that the field of microcredit and microfinance in Europe is still largely unexplored and, in any case, has vast potential for development.

One aspect which the Capacity Building project has been able to strongly highlight for the purposes of future development of microcredit 
is the need to strengthen the synergies between public authorities and territorial entities - in particular, financial intermediaries and notfor-profit organisations. It has been confirmed that establishing territorial networks for microcredit is a "winning" factor, since it gives added value to public planning through the development of ad hoc microfinancial instruments and the accompaniment of non-financial services for support, mentoring and monitoring.

In sum - and on the basis of the recommendations of this research - I believe that the results of the Capacity Building project will be promoted at the national and European level, having tables of discussion with the European Commission, regional authorities and market players, to arrive at new and more ambitious objectives already in the 20142020 programming period, through the strengthening of competences not only of public institutions but also of stakeholders. I consider, for example, the possibility of providing technical assistance to "regulators" of microcredit and microfinance, of developing a central credit register and a scoring model for microcredit, of strengthening the expertise of service providers accompanying measures for microcredit, also in view of a public system of certification, of the financing of networks, of encouraging the exchange of experiences between microcredit operators for the research of new technologies or the definition of new microfinance products and services and of training the staff of new microcredit intermediaries.

The processing of these basic themes can be effectively coordinated by the European Commission in close consultation with national authorities and supported by specialist organisations (e.g., the National Agency for Micro-credit in Italy) and with all stakeholders in the microfinance sector, such as financiers, investors, customers and organisations within the territory.

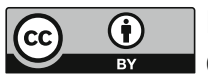

Except where otherwise noted, this work is licensed under a Creative Commons Attribution 3.0 Unported License. To view a copy of this license, visit http://creativecommons.org/licenses/by/3.0/ 